\title{
Combination of Optimal Conductor Selection and Capacitor Placement in Radial Distribution Systems Using PSO Method
}

\author{
Mahdi Mozaffari Legha ${ }^{* 1, a}$, Farzaneh Ostovar ${ }^{2, b}$, Mohammad Mozaffari Legha ${ }^{2}$ \\ ${ }^{1}$ Department of Power Engineering, Shadegan Branch, Islamic Azad University, Shadegan, Iran \\ ${ }^{2}$ Department of Power Engineering, Shadegan Branch, Islamic Azad University, Shadegan, Iran \\ ${ }^{3}$ Department of Power Engineering, Kerman Branch, Islamic Azad University, Kerman, Iran \\ Mozaffari.m@shirazu.ac.ir ${ }^{\text {a }}$; Farzaneh.ostovar@yahoo.com ${ }^{\text {b; }}$ Mozaffari50@gmail.com ${ }^{\mathrm{c}}$
}

\begin{abstract}
In This paper presents an approach for optimal placement and sizing of fixed capacitor banks and also optimal conductor selection in radial distribution networks for the purpose of economic minimization of loss and enhancement of voltage. The objective function includes the cost of power losses, voltage profile, fixed capacitor banks and also type of conductor selection. Constraints include voltage limit, maximum permissible carrying current of conductors, size of available capacitors and type of conductors. The optimization problem is solved by the Imperialism Competitive algorithm method and the size and site capacitor banks and type of conductors is determined. To demonstrate the validity of the proposed algorithm, computer simulations are carried out on actual power network of Kerman city, Iran and the simulation results are presented and discussed.
\end{abstract}

Keywords: PSO Algorithm, Radial Distribution Systems, Loss Reduction, Capacitor placement, Conductor Selection.

\section{الجمع بين موصل الأمثل اختيار وتنسيب المكثفات في أنظمة توزيع شعاعي عن طريق PSO الطريقة}

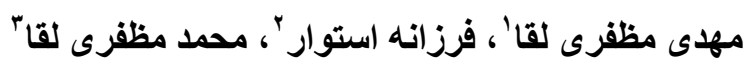

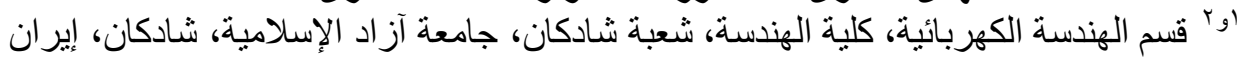

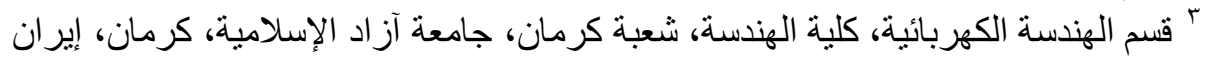

Mozaffari.m@shirazu.ac.ir a ; Farzaneh.ostovar@yahoo.com ${ }^{\text {b; }}$; Mozaffari50@gmail.com ${ }^{\text {c }}$

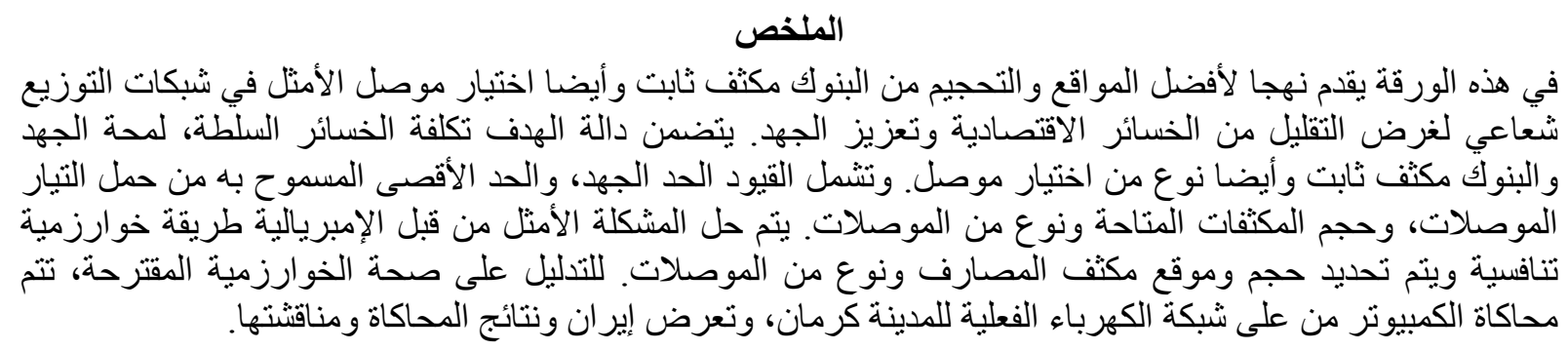

\section{Introduction}

The main objective of an electrical distribution system (EDS) is providing a reliable and cost-effective service to consumers with considering power quality within standard ranges. Thus, it is necessary to properly plan the EDS and thus evaluate several aspects such as, new equipment installation cost, equipment utilization rate, and quality of service, reliability of the distribution system and loss minimization, considering an increase of system loads, and 
newly installed loads for the planning horizon [1]. The loss minimization in distribution systems has assumed greater significance recently since the trend towards distribution automation will require the most efficient operating scenario for economic viability variations. The power losses in distribution systems correspond to about $78 \%$ of total losses in electric power systems (Mahdi Mozaffari Legha et al, 2012).

The advantages with the addition of shunt capacitors banks are to improve the power factor, feeder voltage profile, Power loss reduction and increases available capacity of feeders. Therefore it is important to find optimal location and sizes of capacitors in the system to achieve the above mentioned objectives. Since, the optimal capacitor placement is a complicated combinatorial optimization problem, many different optimization techniques and algorithms have been proposed in the past. (Baghzouz and Ertem, 1990) proposed the concept that the size of capacitor banks was considered as a continuous variable. (H. $\mathrm{Ng}$ et al, 2000) proposed the capacitor placement problem by using fuzzy approximate reasoning. (Ji Pyng Chiou et al, 2006) proposed the variable scale hybrid differential evolution algorithm for the capacitor placement in distribution system. However, considered only the losses in the lines and the quantification were defined for the line losses only.

There are several parameters to be taken into account to model the conductor size selection (CSS) problems such as: conductor's economic life, discount rate, cable and installation costs and type of circuit (overhead or underground). Dynamic programming approach was utilized to solve the CSS problem in (R. S. Rao, 2010). They presents models to represent feeder cost, energy loss and voltage regulation as a function of a conductor cross-section. In (M. Vahid, et al, 2009), the conductor size selection performed with consideration of financial and engineering criteria in the feeder. In (G. J. Anders et al, 1993) and (M. Ponnavaikko et al, 1982) the CSS problem is solving using heuristic methods. Reference
(G. J. Anders et al, 1993) uses a selection phase by means of economic criteria, followed by a technical selection using a sensitivity index that seeks to ensure a feasible operation of the EDS, whereas (M. Ponnavaikko et al, 1982) presents a heuristic method using a novel sensitivity index for the reactive power injections. The heuristic methods are robust, easily applied; however, they normally converge to a local optimum solution. In (S. Mandal et al, 2002), a mixed integer linear model for the problem of conductor selection size in radial distribution systems is presented.

In this paper, a combination of both capacitor placement and conductor selection methods is developed to reduce the loss of a distribution network. In this method the objective function of capacitor placement and conductor selection is to reduce the power loss within minimum costs and enhancing the voltage profile. The constraints are voltage limits, allowable current energy capacity of selected conductors. To solve this optimization problem, PSO method is used. To demonstrate the validity of the proposed algorithm, computer simulations are carried out on actual power network of Kerman Province, Iran and the simulation results are presented and discussed. The results show that proposed objective function minimizes the loss of the system by considering all of the constraints and incorporating capacitors and conductor's selection.

\section{PROBLEM FORMULATIONS 2.1.Power Flow Analysis Method}

Power flow evaluation includes the calculation of bus voltages and line flows of a network. A single-phase representation is adequate because power systems are usually balanced. Associated with each bus, there are four quantities to be determined or specified: the real and reactive powers, the voltage magnitude and phase angle. Figure 1 shows an m-bus radial distribution system wherein bus i has a load and a shunt capacitor (S. Mandal and et al). 


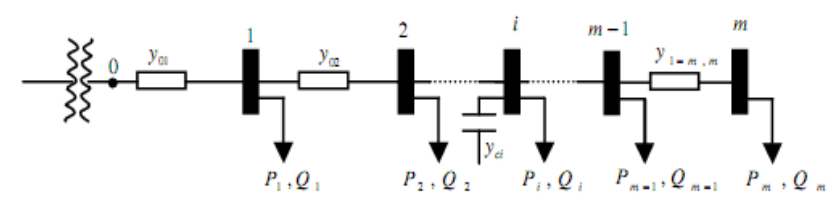

Fig. 1: Single line diagram of a radial distribution feeder

Notation:

$Y_{i, i+1}=1 /\left(R_{i, i+1}+j X_{i, i+1}\right)$; Admittance of the line section between buses $i$ and $i+1, R_{i, i+1}$, $\mathrm{X}_{\mathrm{i}, \mathrm{i}+1}$; Resistance and reactance of the line connecting buses $\mathrm{i}$ and $\mathrm{i}+1, \mathrm{P}_{\mathrm{i}}, \mathrm{Q}_{\mathrm{i}}$; Load active and reactive powers at bus i. At bus i, we have

$\mathrm{P}_{\mathrm{i}}-\mathrm{Q}_{\mathrm{i}}=\mathrm{V}_{\mathrm{i}}^{*} \mathrm{I}_{\mathrm{i}}$

Where $I_{i}$ is positive when it flows into the system and $m$ is the number of buses in the feeder. The bus voltages and line losses can be solved by the Gauss-Seidel iterative method employing the following formula (M. J. Rider et al, 2012):

$\mathrm{V}_{\mathrm{i}}^{(\mathrm{k}+1)}=\frac{1}{\mathrm{Y}_{\mathrm{ij}}}\left(\frac{\mathrm{P}_{\mathrm{i}}-\mathrm{j} \mathrm{Q}_{\mathrm{i}}}{\mathrm{V}_{\mathrm{i}}^{*(\mathrm{k})}}-\sum_{\substack{\mathrm{n}=1 \\ \mathrm{n} \neq \mathrm{m}}}^{\mathrm{m}} \mathrm{Y}_{\mathrm{in}} \mathrm{V}_{\mathrm{n}}\right) \mathrm{i}=1, \ldots, \mathrm{m}$

At the power frequency, the power loss in the line section between buses $i$ and $i+1$ may then be computed by:

$\mathrm{P}_{(\mathrm{i}, \mathrm{i}+1)}=\mathrm{R}_{\mathrm{i}, \mathrm{i}+1} \cdot\left[\left|\mathrm{V}_{\mathrm{i}+1}-\mathrm{V}_{\mathrm{i}}\right| \cdot\left|\mathrm{Y}_{\mathrm{i}, \mathrm{i}+1}\right|\right]^{2}$

The purpose of placing compensating capacitors and optimal conductors is to obtain the lower the total power loss and bring the bus voltages within their specified while minimizing the total cost. The total power loss is given by Eq. (4); (M. J. Rider et al, 2012).

$$
\mathrm{P}_{\mathrm{i}}=\sum_{\mathrm{i}=0}^{\mathrm{m}-1} \mathrm{P}_{(\mathrm{i}, \mathrm{i}+1)}
$$

The Backward Sweep calculates the current injected into each branch as a function of the end node voltages. It performs a current summation while updating voltages. Bus voltages at the end nodes are initialized for the first iteration. Starting at the end buses, each branch is traversed toward the source bus updating the voltage and calculating the current injected into each bus. These calculated currents are stored and used in the subsequent Forward Sweep calculations. The calculated source voltage is used for mismatch calculation as the termination criteria by comparing it to the specified source voltage. The Forward Sweep calculates node voltages as a function of the currents injected into each bus. The Forward Sweep is a voltage drop calculation with the constraint that the source voltage used is the specified nominal voltage at the beginning of each forward sweep. The voltage is calculated at each bus, beginning at the source bus and traversing out to the end buses using the currents calculated in previous the Backward Sweep [5]. Flowchart of the BackwardForward sweep method is depicted in Figure 2.

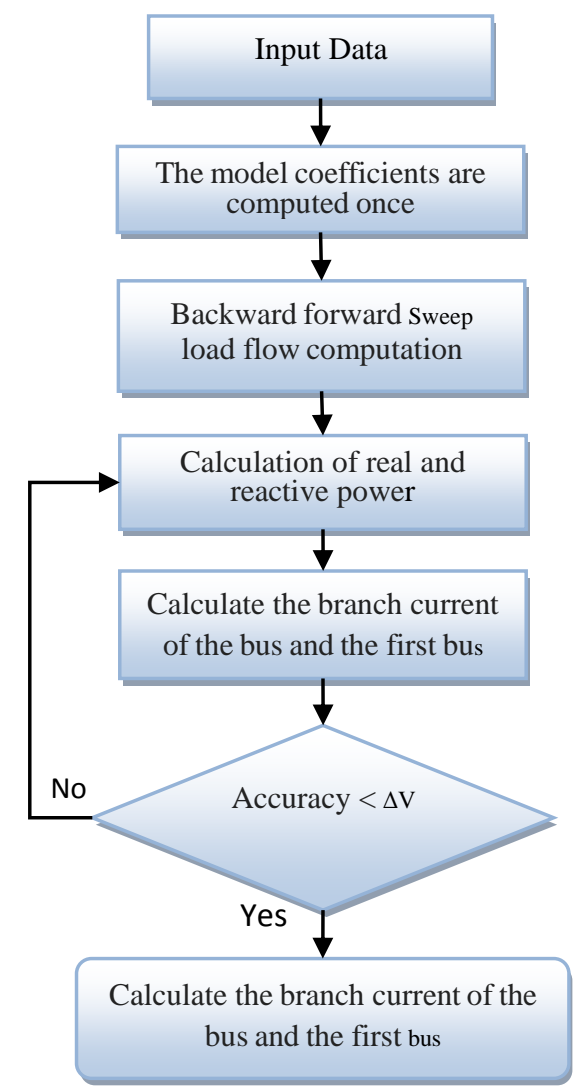

Figure 1: Flowchart of the Backward-Forward sweep method 


\subsection{Formulation}

\section{- Capacitor Placement}

Considering the practical capacitors, there exists a finite number of standard sizes which are integer multiples of the smallest size $\mathrm{Q}_{0}{ }^{\mathrm{c}}$. Besides, the cost per Kvar varies from one size to another. In general, capacitors of larger size have lower unit prices. The available capacitor size is usually limited to $\mathrm{Q}_{\mathrm{c}}^{\mathrm{max}}=\mathrm{LQ}_{\mathrm{c}}$

Where $\mathrm{L}$ is an integer. Therefore, for each installation location, there are $\mathrm{L}$ capacitor sizes $\left[1 \mathrm{Q}_{\mathrm{c}}, 2 \mathrm{Q}_{\mathrm{c}}, 3 \mathrm{Q}_{\mathrm{c}}, \ldots, \mathrm{LQc}\right]$ available. Given the annual installation cost for each compensated bus, the total cost due to capacitor placement and power loss change is written as

$$
\mathrm{fl}=\mathrm{K}_{\mathrm{p}} \times \mathrm{P}_{\mathrm{T}}^{\mathrm{LOSS}}+\sum_{\mathrm{i}}^{\mathrm{c}}\left(\mathrm{K}_{\mathrm{cf}}+\mathrm{K}_{\mathrm{i}}^{\mathrm{c}} \mathrm{Q}_{\mathrm{i}}^{\mathrm{c}}\right)
$$

Where $\mathrm{n}$ is number of candidate locations for capacitor placement, $\mathrm{Kp}$ is the equivalent annual cost per unit of power loss in $\$ /(\mathrm{Kw}-$ year); $\mathrm{K}_{\mathrm{cf}}$ is the fixed cost for the capacitor placement. Constant $K_{i}^{c}$ is the annual capacitor installation cost, and, $\mathrm{i}=1,2, \ldots, \mathrm{n}$ are the indices of the buses selected for compensation. The bus reactive compensation power is limited to

$$
\mathrm{Q}_{\mathrm{i}}^{\mathrm{c}} \leq \sum_{\mathrm{i}=1}^{\mathrm{n}} \mathrm{Q}_{\mathrm{Li}}
$$

Where $1 Q_{c}$ and $L Q_{c}$ are the reactive power compensated at bus $\mathrm{i}$ and the reactive load power at bus i, respectively.

\section{- Conductor Type Selection}

Considering the objective is selection of conductor's size from the available size in each branch of the system which minimizes the sum of depreciation on capital investment and cost of energy losses while maintaining the voltages at different buses within the limits. In this case, the objective function with conductor $c$ in branch $i$ is written as $\mathrm{f} 2=\mathrm{CE}(\mathrm{i}, \mathrm{c})+\gamma^{*} \mathrm{~A}(\mathrm{c}) *\{\mathrm{C}(\mathrm{c})+\mathrm{L}(\mathrm{i})\}$

Where CE $(\mathrm{i}, \mathrm{c})$ is the Cost of Energy Losses, $\mathrm{n}$ is buss number, $\mathrm{i}$ is the branch number and $\mathrm{w}$ is the weighting factor[13]. The annual cost of loss in branch $i$ with conductor type $k$ is,

$\mathrm{CE}(\mathrm{i}, \mathrm{c})=\mathrm{P} \mathrm{L}(\mathrm{i}, \mathrm{c}) *\left\{\mathrm{KP}+\mathrm{KE} * L_{S F} * \mathrm{~T}\right\}$

Where $K_{p}$ is annual demand cost due to Power Loss $(\$ / \mathrm{kW}), \mathrm{K}_{\mathrm{E}}$ is annual cost due to Energy Loss $(\$ / \mathrm{kWh}), \delta$ is Loss factor, ( PL $(\mathrm{i}, \mathrm{c})$ ) is real Power Loss of branch $i$ under peak load conditions with conductor type $c$ and $T$ is the time period in hours (8760 hours). Where $\mathrm{L}_{\mathrm{SF}}$ is Interest and depreciation factor, $\mathrm{C}_{\mathrm{c}}$ is cost of type conductor $(\$ / \mathrm{km}), \mathrm{A}(\mathrm{c})$ is crosssectional area of $c$ type conductor and L(i) is length of branch i $(\mathrm{km})$.

\section{Objective Function}

In each optimization problem, objective function should be defined. Eq. (11) illustrates the proposed objective function in this paper. This objective function aims at minimizing the total annual cost due to capacitor placement, conductor selection and power losses with constraints that include limits on voltage Eq. (13), maximum permissible carrying current of conductors Eq. (14), size of installed capacitors and type of selected conductors. These constraints are added as penalty functions to the objective function.

$\mathrm{F}=\mathrm{f} 1+\mathrm{f} 2$

$\mathrm{V}_{\min } \leq\left|\mathrm{V}_{\mathrm{i}}\right| \leq \mathrm{V}_{\max }$

$\mathrm{I}_{(1)} \leq \mathrm{I}_{\max (1)}$

Where:

$\mathrm{V}_{\min }, \mathrm{V}_{\max }:$ minimum and maximum permissible bus voltage. $I_{\text {max }}^{l}$ : Maximum permissible carrying current of installed conductors in $\mathrm{L}^{\text {th }}$ section. The flow chart of proposed method is depicted in Figure 3. 


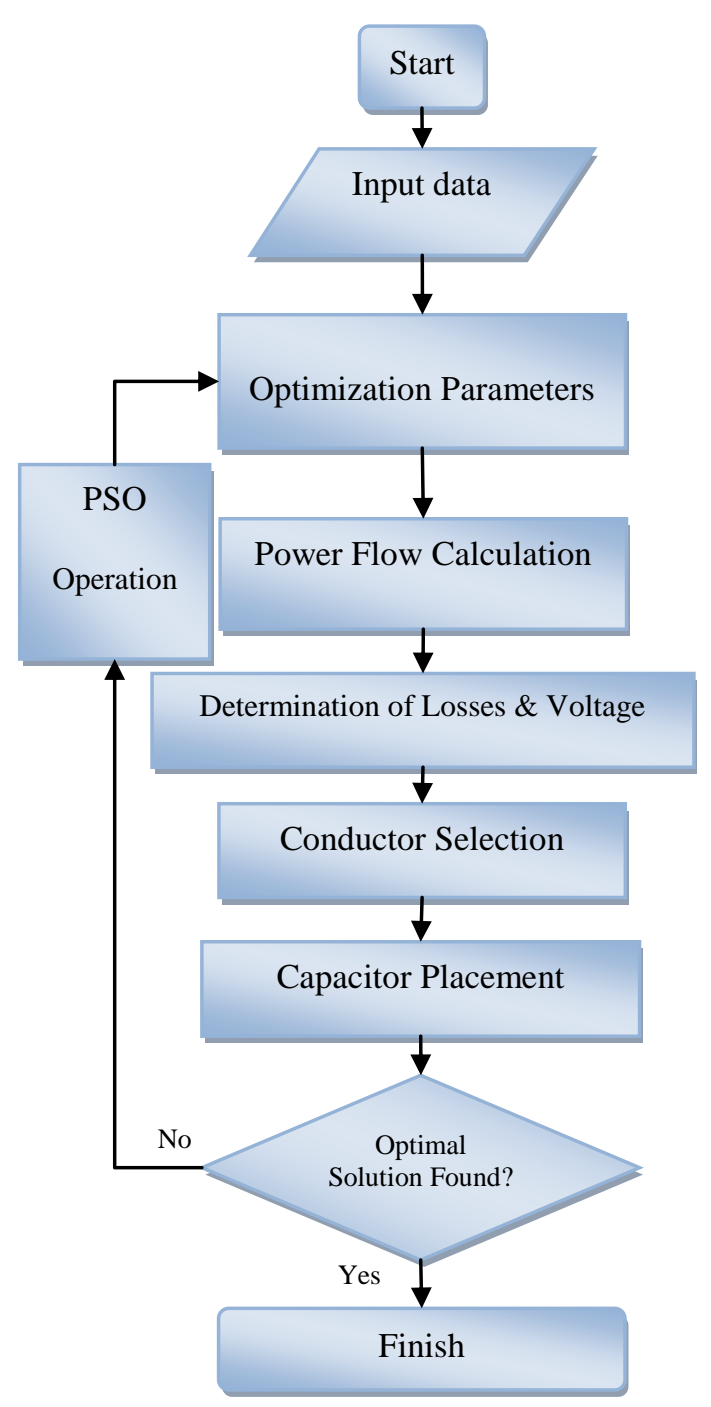

Figure 3: Flowchart of the proposed method

\section{PSO Algorithm}

PSO is a population based stochastic optimization technique developed by Eberhart and Kennedy in 1995 [12-13]. The PSO algorithm is inspired by social behavior of bird flocking or fish schooling. The system is initialized with a population of random solutions and searches for optima by updating generations. However, unlike GA, PSO has no evolution operators such as crossover and mutation. In PSO, the potential solutions, called particles, fly through the problem space by following the current optimum particles. Compared to GA, the advantages of PSO are that PSO is easy to implement and there are few parameters to adjust. PSO has been successfully applied in many areas [14]. The standard PSO algorithm employs a population of particles. The particles fly through the ndimensional domain space of the function to be optimized. The state of each particle is represented by its position xi $=(x i 1, x i 2, \ldots$, xin ) and velocity $v i=(v i 1, v i 2, \ldots$, vin $)$, the states of the particles are updated. The three key parameters to PSO are in the velocity update equation (13). First is the momentum component, where the inertial constant $\mathrm{w}$, controls how much the particle remembers its previous velocity [14]. The second component is the cognitive component. Here the acceleration constant $\mathrm{C} 1$, controls how much the particle heads toward its personal best position. The third component, referred to as the social component, draws the particle toward swarm's best ever position; the acceleration constant $\mathrm{C} 2$ controls this tendency. The flow chart of the procedure is shown in Figure 4.

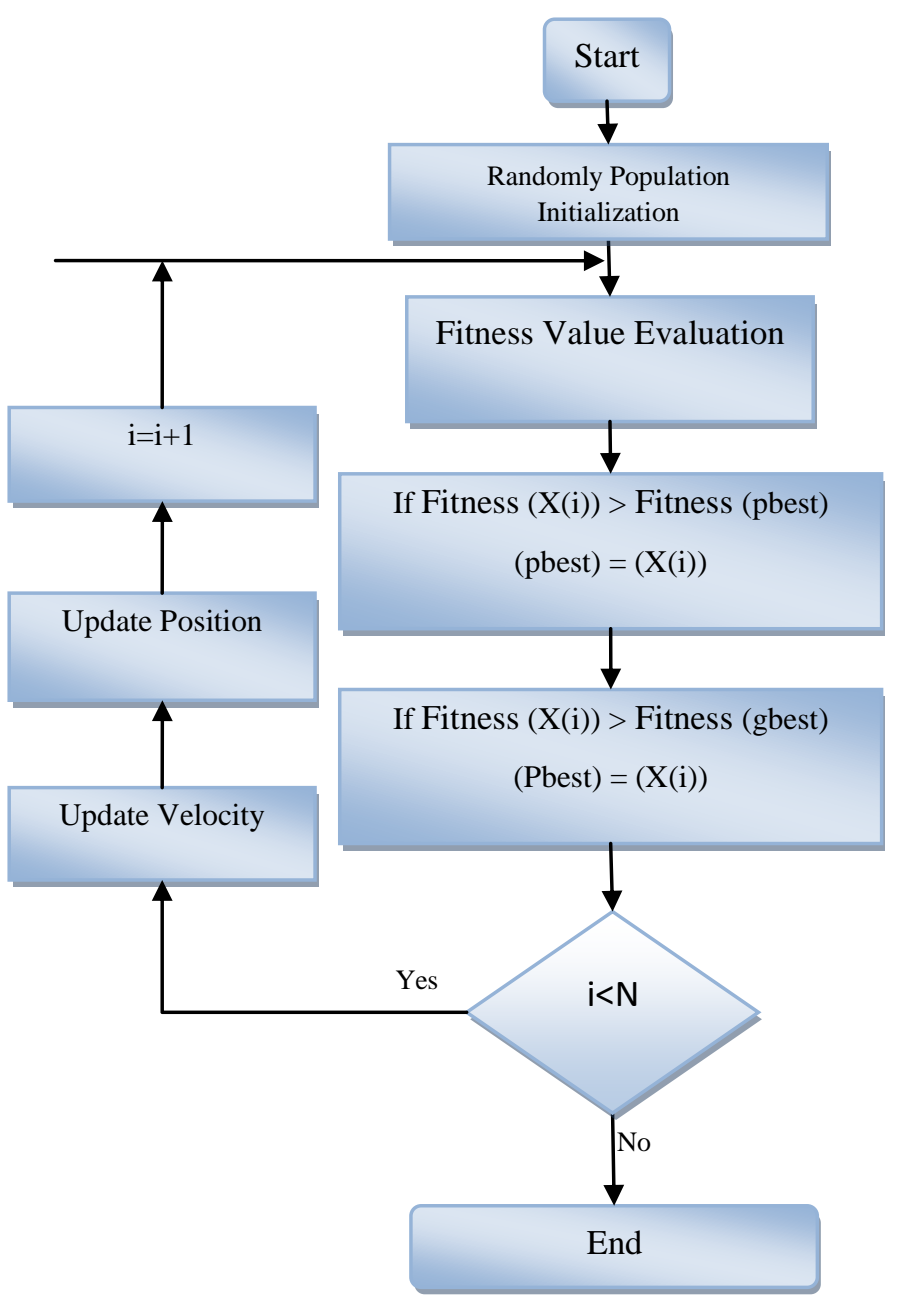

Figure 4: Flowchart of the proposed PSO algorithm 


\section{Tests and Results}

To study the proposed method, actual power network of Kosar feeder of Kerman Province, Iran is simulated in Cymedist. Figure 5 illustrates the single-line diagram of this network. The base values of the system are taken as $20 \mathrm{kV}$ and 20MVA. The details of the distribution conductors are given in table 1. The system consists of 60 distribution transformers with various ratings. The details of the distribution transformers are given in table 2. The total connected load on the system is $2550 \mathrm{KVA}$ and the peak demand for the year is $2120 \mathrm{KVA}$ at a PF of $0.8 \mathrm{lag}$.

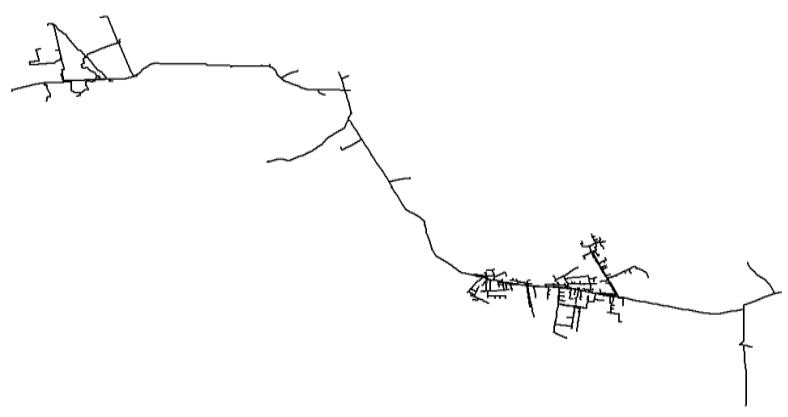

Figure 5: Single-line diagram of actual power network of Kosar feeder of Kerman Province in Cymedist

Table 1: Conductor properties

\begin{tabular}{|c|c|c|c|c|c|}
\hline Type & $\begin{array}{c}\mathrm{R} \\
{[\Omega / \mathrm{km}} \\
]\end{array}$ & $\begin{array}{c}X \\
{[\Omega / \mathrm{km}} \\
]\end{array}$ & $\begin{array}{c}\mathrm{Cma} \\
\mathrm{x}[\mathrm{A}]\end{array}$ & $\begin{array}{c}\mathrm{A} \\
{[\mathrm{mm} 2} \\
]\end{array}$ & $\begin{array}{c}\text { Cost } \\
\text { [Toman/ } \\
\mathrm{m}]\end{array}$ \\
\hline Hyena & $\begin{array}{c}0.157 \\
6 \\
\end{array}$ & $\begin{array}{c}0.227 \\
7 \\
\end{array}$ & 550 & 126 & 2075 \\
\hline Dog & $\begin{array}{c}0.271 \\
2\end{array}$ & $\begin{array}{c}0.246 \\
4\end{array}$ & 440 & 120 & 3500 \\
\hline Mink & $\begin{array}{c}0.454 \\
5\end{array}$ & $\begin{array}{c}0.266 \\
4\end{array}$ & 315 & 70 & 2075 \\
\hline
\end{tabular}

Table 2: Details of transformers in the system

\begin{tabular}{|c|c|c|c|}
\hline $\begin{array}{c}\text { Rating } \\
\text { [KVA] }\end{array}$ & 50 & 100 & 250 \\
\hline Number & 5 & 9 & 6 \\
\hline $\begin{array}{c}\text { No load } \\
\text { losses } \\
\text { [watts] }\end{array}$ & 150 & 250 & 480 \\
\hline $\begin{array}{c}\text { Impedance } \\
{[\%]}\end{array}$ & 4.5 & 4.5 & 4.5 \\
\hline
\end{tabular}

The other parameters used in computation process are: $\mathrm{KP}=1.04(\$ / \mathrm{kW}) ; \mathrm{KE}=0.012$ $(\$ / \mathrm{kWh})$. The parameters used in PSO algorithm are: Number of Decate is 33; Population size is 100; Number of Empire 10; Revolution rate is 0.1 . Also, loss factor, which represents adequately the energy losses for the load level in terms of the maximum power losses are selected.

The results of conductor selection are shown in Table 3. Initially, a load flow was run for the case study in both fundamental frequency and frequencies without installation of capacitor. Table 4 depicts the locations and capacity of capacitor banks using artificial bee colony algorithm. As it is clear, all the obtained values confines with all the considered constraints. The obtained penetration lever is 0.27 , which is less than the assumed allowable value.

Table 3: Conductor selection results

\begin{tabular}{|c|c|c|}
\hline $\begin{array}{c}\text { Conductor } \\
\text { Design Method }\end{array}$ & Type & Branch Number \\
\hline \multirow{3}{*}{ Conventional } & Hyena & From 1 to 26 \\
\cline { 2 - 3 } & Dog & Rest of 68 branches \\
\cline { 2 - 3 } & Mink & ---- \\
\hline \multirow{4}{*}{ PSO Based } & Hyena & From 1 to 10 \\
\cline { 2 - 3 } & & From 11 to 23 \\
& Dog & $34,35,36,37$ \\
& & From 44 to 58 \\
\cline { 2 - 3 } & Mink & Rest of 68 branches \\
\hline
\end{tabular}

Table 4: Optimal place and capacity of capacitor banks

\begin{tabular}{|c|c|}
\hline Location [\#bus] & Capacity [Mvar] \\
\hline 7 & 0.1 \\
\hline 13 & 0.15 \\
\hline 31 & 0.15 \\
\hline 54 & 0.35 \\
\hline 68 & 0.25 \\
\hline
\end{tabular}

The voltage profile in the system after PSO implementation is compared with Conventional conductor design and capacitor placement depicted in Figure 6. The costs based on conductor selection and capacitor placement are compared in Table 5. The real power loss reductions are $15392.38579 \mathrm{~kW}$, which is approximately $8.5 \%$ in compare with the Conventional design for PSO respectively. 


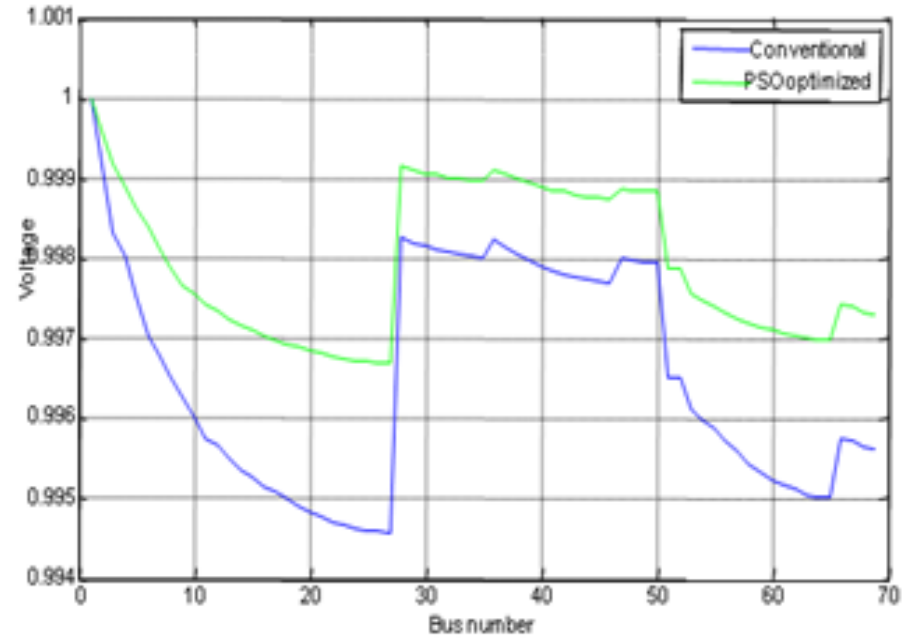

Figure 6: Voltage profiles of 69-bus system

Table 8: Obtained Loss results

\begin{tabular}{|c|c|}
\hline Method & $\begin{array}{c}\text { Total Loss } \\
{[\mathrm{KW}]}\end{array}$ \\
\hline Network Conventional & 32453.24452 \\
\hline Network PSO Optimized & 15392.38579 \\
\hline
\end{tabular}

\section{Conclusion}

In this paper, the conductor selection has been incorporated in the conventional optimal capacitor placement. By making a new objective function and solving the optimization problem by PSO method, the size and place of the capacitors and the conductors has been defined. The method has been applied to a sample radial network and the results show the reduction of total costs in addition to the power loss reduction. According to the results, the bus voltages of the ending buses are in the permissible limits. The real power loss reductions are 606.7364 $\mathrm{kW}$, which is approximately $5.6 \%$ in compare with the Conventional design for PSO respectively.

\section{References}

[1] M. Mozaffari Legha, (2011) Determination of exhaustion and junction of in distribution network and its loss maximum, due to geographical condition, MS.c Thesis. Islamic
Azad University, Saveh Branch, Markazi Province, Iran.

[2] Mahdi Mozaffari Legha, Farzaneh Ostovar, "Analysis and Reconductoring of Overhead Conductors with Considering aging for Radial Distribution Systems Using Imperialist competitive Algorithm", International Journal of Pure and Applied Sciences and Technology, Vol. 20, No. 1, January 2014, pp. 1-8.

[3] Mahdi Mozaffari Legha, Rouhollah Abdollahzadeh, Ardalan Zargar, Mostafa Shadfar. "Effective method for optimal allocation of distributed generation units in radial electric power systems by genetic algorithm and imperialist competitive algorithm", International Journal on Technical and Physical Problems of Engineering (IJTPE), Issue 15, Vol. 5, No. 2, pp. 70-74, June 2013.

[4] R. S. Rao, "Optimal conductor selection for loss reduction in radial distribution systems using differential evolution," Int. J. Eng. Sci. Technol., vol. 2, no. 7, pp. 2829-2838, Jul. 2010.

[5] Mahdi Mozaffari Legha and et al, "A new hybrid particle swarm optimization approach for sizing and placement enhancement of distributed generation' IEEE Conference, 2155-5516; Pages 1277 - 1281.

[6] Mahdi Mozaffari Legha,;"Optimal Conductor Selection of Radial Distribution Networks Using GA Method" CIRED Regional - Iran, Tehran, 13-14 Jan 2013; Paper No: 12-F-5000320 .

[7] Mahdi Mozaffari Legha, Marjan Tavakoli, Farzaneh Ostovar, Milad Askarihashemabadi, "Capacitor Placement in Radial Distribution System for improve network efficiency Using Artificial Bee Colony“, International Journal of Engineering Research and Application, Vol. 3, Issue 6, Nov-Dec 2013, pp.01-05

[8] Mahdi Mozaffari Legha, Rouhollah Abdollahzadeh, Ardalan Zargar, Mohammad Mozaffari Legha," "Cocnductor Size Selection in Planning of Radial Distribution System for Productivity Improvement Using Imperialist Compotitive Algorithm", International Journal on Technical and Physical Problems of Engineering (IJTPE), Issue 15, Vol. 5, No. 2, June 2013, pp. 65-69.

[9] Mahdi Mozaffari Legha, Houman Gadari1, "Technical and Economical Evaluation of Solar Plant for Electricity Supply Anar City Residential Customers", Middle-East Journal of Scientific Research, pp. 455-460, 2013.

[10] M. Vahid, N. Manouchehr, S. D. Hossein, and A. Jamaleddin, "Combination of optimal 
conductor selection and capacitor placement in radial distribution systems for maximum loss reduction," in Proc. 2009 IEEE Int. Conf. Industrial Technology, Gippsland, Australia, Feb. 10-13, 2009, pp. 01-05.

[11] G. J. Anders, M. Vainberg, D. J. Horrocks, S. M. Foty, J.Motlis, and J. Jarnicki, Parameters affecting economic selection of cable sizes," IEEE Trans. Power Del., vol. 8, no. 4, pp. 1661-1667, Oct. 1993.

[12] M. Ponnavaikko and K. S. Prakasa, "An approach to optimal distribution system planning through conductor gradation," IEEE Trans. Power App. Syst., vol. PAS-101, no. 6, pp. 1735-1742, Jun. 1982.

[13] S. Mandal and A. Pahwa, "Optimal selection of conductors for distribution feeders," IEEE Trans. Power Syst., vol. 17, no. 1, pp. 192197, 2002.

[14]Z. Wang, H. L. Yu, X.Wang, and H. Song, “A practical approach to the conductor size selection in planning radial distribution systems," IEEE Trans. Power Del., vol. 15, no. 1, pp. 350-354, Jan. 2000.

[15] D. Karaboga, B. Basturk (2007), “A powerful and efficient algorithm for numerical function optimization: artificial bee colony (ABC) algorithm",Journal of Global Optimization, vol. 39, pp. 459-471.

[16]D. Karaboga, B. Basturk (2008), "On the performance of artificial bee colony (ABC) algorithm", Applied Soft Computing, vol. 8 pp. 687-697.

[17] B. Basturk, D. Karaboga (2006), “An artificial bee colony (ABC) algorithm for numeric function optimization", IEEE Swarm Intelligence Symposium 2006, May 12-14, Indianapolis, IN, USA.

[18]H.A. Shayanfar, H. Shayeghi, A. Jali, "Takagi-

[19] Sugeno Fuzzy Parallel Distribution Compensation Based Three-Area LFC Design", International Journal on Technical and Physical Problems of Engineering (IJTPE), Issue 8, Vol. 3, No. 3, pp. 55-64, September 2011.

[20]M. J. Rider, M. Lavorato, R. Romero, "Optimal Conductor Size Selection and Reconductoring in Radial Distribution Systems Using a Mixed-Integer LP Approach", Power Systems, IEEE Transactions on,(doi: 10.1109/TPWRS.2012.2201263),2012

[21]F. Mendoza, D. Requena, J. L. BernalAgustin, and J. A. Dominguez- Navarro, "Optimal conductor size selection in radial power distribution systems using evolutionary strategies," in Proc. IEEE/PES Tranmission \&
Distribution 2006 Latin América, Venezuela, 15-18, 2006, pp. 01-05.

[22] R. Ranjan, A. Chaturvedi, P. S. Solanki, and D. Das, "Optimal conductor selection of radial distribution feeders using evolutionary programming," in Proc. 2003 IEEE Region 10 Conf. Convergent Technologies for the AsiaPacific (TENCON 2003), Bangalore, India, 15-17, 2003, vol. 1, pp. 456-459.

[23] Mahdi Mozaffari Legha , Farzaneh Ostovar, "An Imperialist Competitive Algorithm for Sitting and Sizing of istributed Generation in Radial Distribution Network to Improve Reliability and Losses Reduction"Iraqi Journal for Electrical and Electronic Engineering (IJEEE), Vol.9 No.1 , 2013, pp. 59-67.

[24] Mahdi Mozaffari Legha, Hassan Javaheri, Mohammad Mozaffari Legha, "Optimal Conductor Selection in Radial Distribution Systems for Productivity Improvement Using Genetic Algorithm "Iraqi Journal for Electrical and Electronic Engineering (IJEEE), Vol.9 No.1 , 2013, 29-36.

[25] N. Medina, M.M. Qi, L. Butler-Purry, K.L. A Three Phase Load Flow Algorithm for Shipboard Power Systems (Sps), 2003.

[26] Web site Electrical Power Engineering Specialists, REPORTs, 2014. Available at: <http://www.drmozaffarilegha.com.com> [accessed 01.01.2014]

[27] Mahdi Mozaffari Legha,; "Optimal Conductor Selection of Radial Distribution Networks Using GA Method" CIRED Regional - Iran, Tehran, 13-14 Jan 2013; Paper No: 12-F-5000320.

[28] Mahdi Mozaffari Legha, Moein khosravi, Mohammad Hossein Armand, Mahdiyeh Azh," "Optimization of Location and Capacity DGs Using HPSO Approach Case Study on the Electrical Distribution Network of north Kerman Province", Middle-East Journal of Scientific Research, pp. 461-465, 2013.

[29] Mahdi Mozaffari Legha, Rouhollah Abdollahzadeh, Ardalan Zargar, Mostafa Shadfar. "Effective method for optimal allocation of distributed generation units in radial electric power systems by genetic algorithm and imperialist competitive algorithm", International Journal on Technical and Physical Problems of Engineering (IJTPE), Issue 15, Vol. 5, No. 2, pp. 70-74, June 2013.

[30] Mahdi Mozaffari Legha, "Determination of exhaustion and junction of in distribution network and its loss maximum, due to geographical condition", MS.c Thesis; Islamic 
Azad University, Saveh Branch, Markazi Province, Iran; pp. 1-300, Aug 2011.

[31]O. Amanifar, M.E. Hamedani Golshan, "Optimal Distributed Generation Placement and Sizing for Loss THD Reduction and Voltage Profile Improvement in Distribution Systems Using Particle Swarm Optimization and Sensitivity Analysis", International Journal on Technical and Physical Problems of Engineering (IJTPE), Issue 7, Vol. 3, No. 2, pp. 47-53, March 2011.

[32]T. Gönen, Electric Power Distribution Systems Engineering. New York: McGrawHill, 1986. 